\title{
La enfermedad de Alzheimer
}

\author{
Alzheimer's disease \\ Eva M. Molina-Trinidad* ${ }^{a}$, Gabriela Muñoz Reyes ${ }^{b}$, Marco A. Becerril Flores ${ }^{c}$,

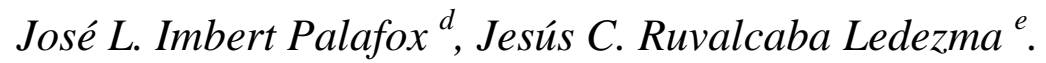

\begin{abstract}
:
Alzheimer's disease (AD) is a progressive disease that is reflected in markers through evaluation modalities, including neuroimaging, cognitive tests and adaptive function evaluation. The objective of this study is to know the symptoms, treatment and possible causes of Alzheimer's disease and the effects on the social environment of people who suffer. In conclusion we think that it is completely true to consider Alzheimer's disease as "the most dangerous, incurable and difficult to face senile dementia in a family environment", since the disease is associated with other pathological disorders that can lead to death and that the knowledge we have about her is still a bit uncertain.
\end{abstract}

Keywords:

Alzheimer, neurological disease, dementia, symptoms, treatment.

\section{Resumen:}

La enfermedad de Alzheimer (EA) es una enfermedad progresiva que se refleja en marcadores a través de las modalidades de evaluación, incluida la neuroimagen, las pruebas cognitivas y la evaluación de la función adaptativa. El objetivo de este estudio es conocer los síntomas, el tratamiento y las posibles causas de la enfermedad de Alzheimer y los efectos en el entorno social de las personas que padecen. En conclusión, nosotros pensamos qué es completamente cierto considerar la enfermedad de Alzheimer como "el tipo demencia senil más peligrosa, incurable y difícil de enfrentar en un entorno familiar", ya que la enfermedad está asociada a otros trastornos patológicos que pueden llevar a la muerte y que los conocimientos que tenemos sobre ella son aún un poco inciertos.

Palabras Clave:

Alzheimer, desorden neurológico, demencia, síntomas, tratamiento.

\section{INTRODUCCIÓN}

El Alzheimer es una enfermedad neurodegenerativa manifestada cuando las células nerviosas del encéfalo mueren, afectando la corteza cerebral y el hipocampo; fue descubierta por el Dr. Alois Alzheimer.

Es una demencia que en los primeros estadios se manifiesta con alteraciones del lenguaje, falta de memoria y desorientación. Con el tiempo avanza, y en estadios tardíos afecta la memoria a largo plazo. Es una enfermedad frecuente en adultos mayores de 65 años, los cuales manifiestan deterioro en la memoria, en el pensamiento y en el comportamiento.

En 1910 el Dr. Kraepelin denomina Enfermedad de Alzheimer a la alteración que manifestaban ciertos pacientes respecto a la pérdida de memoria, desorientación, alucinaciones y muerte provocada por una atrofia cerebral progresiva que daña todas las

\footnotetext{
a *Autor de correspondencia, Universidad Autónoma del Estado de Hidalgo, Instituto de Ciencias de la Salud, https://orcid.org/0000-00019654-5918, Email: eva_molina8849@uaeh.edu.mx

${ }^{\mathrm{b}}$ Universidad Autónoma del Estado de Hidalgo, Instituto de Ciencias de la Salud, estudiante.

c Universidad Autónoma del Estado de Hidalgo, Instituto de Ciencias de la Salud, Email: mbecerril_65@yahoo.com

${ }^{\mathrm{d}}$ Universidad Autónoma del estado de Hidalgo. Instituto de Ciencias de la Salud, Email: imbertox@ @otmail.com

${ }^{\mathrm{e}}$ Universidad Autónoma del Estado de Hidalgo, Instituto de Ciencias de la Salud, Email: dcspjcarlos@ gmail.com
} 
partes del cerebro según estudios realizados en pacientes que presentaban la enfermedad.

A nivel mundial se reportan aproximadamente 47 millones de personas que padecen demencia y cada año se registran 9.9 millones de casos nuevos. La enfermedad de Alzheimer es la demencia más común y se presenta del 60 al $70 \%$ de los casos de demencia. Esta enfermedad influye en la conducta de los cuidadores, de la familia y de la sociedad.

En este trabajo damos a conocer la enfermedad del Alzheimer como una de las demencias que afecta a adultos mayores y que se manifiesta como enfermedad crónica-degenerativa caracterizada por el deterioro de la función cognitiva donde la pérdida de la función cognitiva es precedido por el deterioro del control emocional y del comportamiento social.

La enfermedad de Alzheimer (EA) tiene una incidencia 100 veces mayor que la del cáncer de mama.

Según expertos, es tal su magnitud y ritmo de crecimiento que, como hoy es la diabetes para México, en los próximos años habrá una nueva epidemia: el Alzheimer. Actualmente se estima que al menos 800 mil mexicanos padecen este tipo de demencia, casi $9 \%$ de personas mayores de 60 años. $^{1}$

La EA es la primera causa de demencia, presente entre $40 \%$ y $50 \%$ de los casos. Es la más frecuente de las neurodegeneraciones. En el mundo existen más de 24 millones de personas con demencia y se estiman 4.6 millones de casos nuevos cada año y para el año 2040 aumentará. $^{2}$

El síntoma inicial se manifiesta con la inhabilidad de la memoria, pero suele confundirse con actitudes relacionadas con el proceso de envejecimiento o el estrés. ${ }^{3}$

El Alzheimer es la forma más común de demencia, es incurable. Aparece con mayor frecuencia en personas mayores de 65 años de edad. Los síntomas de la enfermedad como una entidad nosológica definida fueron identificados por Emil Kraepelin, mientras que la neuropatología característica fue observada por primera vez por Alois Alzheimer en $1906 .^{3}$

El deterioro cognitivo leve (DCL) es la fase entre el olvido normal debido al envejecimiento y el desarrollo del mal de Alzheimer. Las personas con DCL tienen ligeros problemas con el pensamiento y con la memoria, hechos que no interfieren con las actividades cotidianas. Con frecuencia, están conscientes del olvido. Cabe decir que no todas las personas con DCL progresan al mal de Alzheimer. ${ }^{4}$ La EA es una entidad heterogénea y puede ser familiar o esporádica. Las formas familiares son relativamente infrecuentes, menos de $1 \%$ y tiene un patrón autosómico dominante (AD). En las formas esporádicas existen antecedentes de demencia en más de $80 \%$ por lo que cree que existe una relación genética como factor de riesgo. Los hallazgos genéticos comenzaron con el descubrimiento de la proteína precursora amiloide (APP) en el cerebro de portadores de Síndrome de Down con deterioro cognitivo. Esta proteína se encontraba en el cromosoma 21 y tenía un patrón de herencia $A D$ con inicio temprano, aunque se ha reportado que es posible de que alteraciones genómicas parecidas en neuronas individuales estén asociadas a patologías neurológicas como en el caso de la EA.

\section{GENERALIDADES}

Estudios en el cerebro humano indican que pacientes con Alzheimer contienen poblaciones celulares con mayor cantidad de ADN, así como copias extra del gen $A P$ (amyloid beta A4 precursor protein), implicado en la enfermedad.

La proteína precursora amiloide (APP) está relacionada con la EA. Se dice que el gen de APP se expresa en la forma más grande cómo un polipéptido de 770 aminoácidos. El empalme alternativo del exón 7 (que codifica el dominio Kurnitz) y del exón 8 (que codifica el antígeno ox-2) 
resulta en un polipéptido de 695 aminoácidos (predomina) o en otro de 751 aminoácidos. ${ }^{1}$

La presencia del gen de la apolipoproteína épsilon (APOE; cromosoma 19) como factor de riesgo para la EA de inicio es conocido. Este gen tiene varios alelos: el 2, el 3 y el 4 . Tanto en sujetos normales como en pacientes que presentan la EA el alelo 2 es el menos frecuente y el más común el alelo 3. En sujetos con EA se observa el alelo E4 con una frecuencia casi igual al 3.2. El gen APOE 4 se puede presentar tanto de forma heterocigótica (inicio de la enfermedad entre 5 y 10 años antes) como homocigoto (inicio de la enfermedad entre 10 y 20 años antes). La APOE se produce predominantemente en los astrocitos ó células gliales y se introduce en la neurona a través de los receptores LDL (glicoproteína transmembranaria que se une de manera específica a apoB-100 y apoE), una vez dentro se une a los ovillos neurofibrilares, ver Fígura 1. Este receptor es la vía común de la $\mathrm{A} 2 \mathrm{M}$, APOE4 y de la LDL. ${ }^{1}$

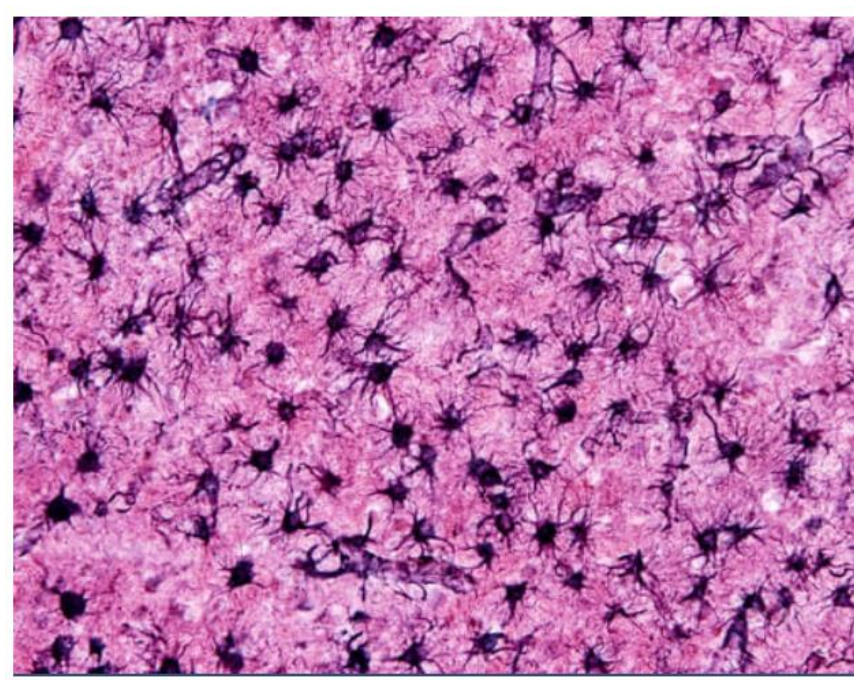

Figura 1. Los astrocitos, un tipo de célula cerebral, son los principales integrantes del grupo de las células gliales.

Por otra parte, la EA se caracteriza por cambios neuropatológicos degenerativos progresivos, con un deterioro global asociado del funcionamiento cognitivo y la personalidad. Los síntomas empeoran con el tiempo y las personas mueren a causa de las complicaciones de la enfermedad debido a infecciones múltiples.

$$
\text { La secuencia patológica comienza }
$$
preferentemente en las estructuras del lóbulo temporal medio, responsable de la memoria y luego progresa a las áreas frontales, temporal y parietal, con preservación relativa de las regiones motoras, regiones corticales sensoriales y regiones subcorticales. ${ }^{4}$

Actualmente existen dos teorías que tratan de explicar los déficits cognitivos de la EA: Teoría de desconexión cortical y Teoría colinérgica. ${ }^{1}$

\section{TEORÍA DE DESCONEXIÓN CORTICAL}

Según en esta teoría existe una degeneración neurofibrilar en la corteza entorrinal, portal cortical del hipocampo (HC) donde se distribuyen las neurobirillas en las cortezas II y IV de manera que el HC queda aislado de la neurocorteza. La enfermedad del EA también está relacionada con la disminución del aminoácido ácido glutámico y otros neuropéptidos presentes en las cortezas de asociación que se correlacionan con la afasia (Trastorno del lenguaje que se caracteriza por la incapacidad o la dificultad de comunicarse mediante el habla, la escritura o la mímica y se debe a lesiones cerebrales), la apraxia (Incapacidad de ejecutar movimientos coordinados sin que exista una causa de origen físico) y la agnosia (Incapacidad para reconocer e identificar la información que llega a través de los sentidos, especialmente la vista), así como los trastornos visuoespaciales y la ejecución de actividades que presentan los pacientes. ${ }^{1,2}$

Metabolismo beta amiloide: el péptido $\beta$ amiloidea es un pequeño fragmento de una proteína transmembranal con función incierta, conocida cómo proteína precursora amiloide (APP) qué se sintetiza en el cromosoma 21. Se creé que esta proteína participa en la traducción de señales. La APP se encuentra en las membranas citoplásmáticas, en los endosomas y en el aparato de 
Golgi, de las células del sistema nervioso y en células sanguíneas. Algunas isoformas de la APP tienen un dominio inhibidor de la proteasa de Kunitz (enzima regladora de la cascada de coagulación). En individuos normales el péptido $\beta$ amiloide se divide en fragmentos por acción enzimática de una proteína llamada secretasa alfa quién divide al péptido endos fragmentos, uno constituye la nexina II y el otro el péptido $\beta$ amiloide constituido de 16 aminoácidos. Este péptido se une a la $\alpha 2$-macroglobilina que indica las señales a las proteínas que serán degradadas dando lugar al complejo $\beta$ amiloide-A2M unido a una proteasa, quién reingresa a las células nerviosas adheridas a A2M por un receptor de membrana qué es común en LDL y a la APOE. También puede haber un desprendimiento del péptidp $\beta$ amieloide de 40 a 42 aminoácidos. Esta fracción sufre transformaciones cómo la pérdida de su estructura helicoidal alfa para unirse a varios péptidos formando el complejo $A B-42$ que después se une al complejo $A B-40$ de hoja plegada. Estos complejos son estables por asociación con otras proteínas como las proteínas amiloídeas componentes del suero (SAP) que solo se degradan en el hígado. La presencia de los cuerpos amiloides induce a la activación inmune de las microglias, que provocan lesiones inflamatorias y debidas a la presencia de radicales libres. Ver la Figura 3.

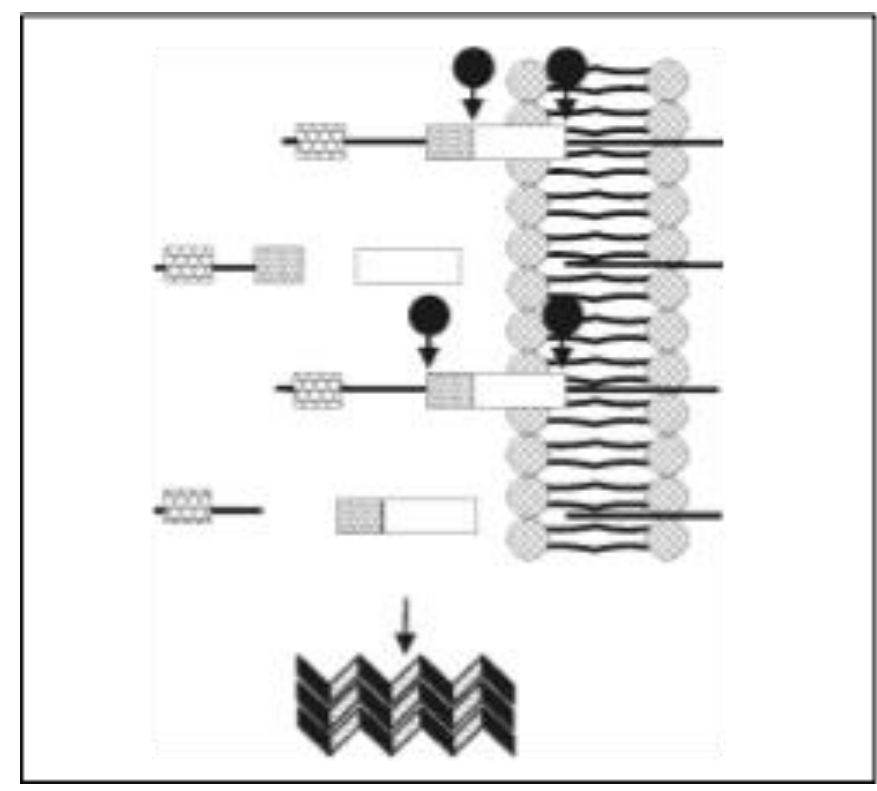

Figura 3. El péptido $\beta$-amiloide forma parte de una proteína transmembranal en donde el extremo amino $\left(\mathrm{NH}_{3}\right)$ es intracelular y el extremo .carboxilo $(\mathrm{COOH})$ es extracelular. La escisión por secretasas alfa y gama producen degradación del péptido 16-42. La escisión alternativa produce el péptido 1-42 que se presenta en forma de hojas plegadas que difícilmente se degrada. ${ }^{2}$

Metabolismo Neurofibrilar: Los ovillos neurobirilares (ONF) se están constituidos por filamentos helicoidales formados por proteínas Tau hiperfosforiladas y por otra proteínas asociadas amicrotúbulos (MAP2) que predominan en dendritas, la ubiquitina y los péptidos $\beta$-amiloide. Las proteínas Tau predominan en los axónes y conforman el grupo de proteínas MAP, qué interactúan con los microtúbulos ensamblando o desarmando los microtúbulos, con el fin de alargar o acortan a los axónes. La hiperfosforilación de las mencionadas proteínas provoca autoagregación de las mismas formando filamentos helicoidales pareados que dificultan el transito axonal con neurodegeneración por apoptosis, cómo en el caso de la EA. Ver Figura 4.

Se cree que la neurodegeneración celular esta asociada con el metabolismo del calcio $\left(\mathrm{Ca}^{2+}\right)$, el desequilibrio de los radicales libres y la toxicidad con aluminio.

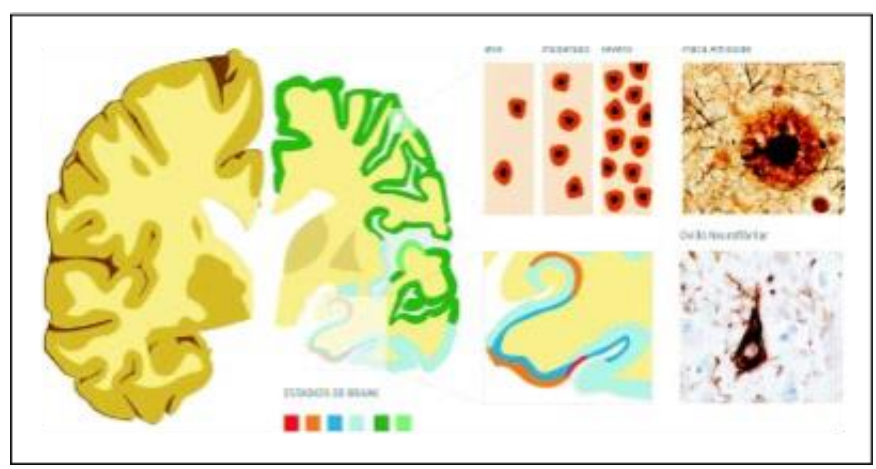

Figura 4. Esque de un hemisferio de un sujeto normal, en la parte izquierda, y un hemisferio de un sujeto con EA, en la parte derecha, Las escalas de coloires representan los estados de ONF de Braak. Los estados I y II sonentorrinales (síntomas leves), estados III y IV son límbicos (deficit amnésico), estados corticales on V y VI (deterioro cortical con asociación). ${ }^{2}$

\section{TEORÍA COLINÉRGICA}

De acuerdo a esta teoría se ha mencionado que en estados avanzados de la enfermedad de $A E$ 
se observa una disminución de más de $90 \%$ de la actividad de la acetilcolinesterasa y en la función del sistema colinérgico. Esto ocasiona el deterioro amnésico inicial y progresivo de la enfermedad.

Se dice que la degeneración selectiva del núcleo basal de Meynert y de los núcleos septal y de la banda diagonal de broca provoca un déficit progresivo de la memoria. Existen evidencias de cambios tempranos en el flujo cerebral regional, lo que pudiera relacionarse con la degeneración colinérgica que tiene un efecto regulador. En la siguiente figura $\mathrm{s}$

e observa el núcleo basal de Meynert que es un grupo de células nerviosas localizado con proyección a la neocorteza cerebral, rico en acetilcolina y colina o-acetiltransferasa.

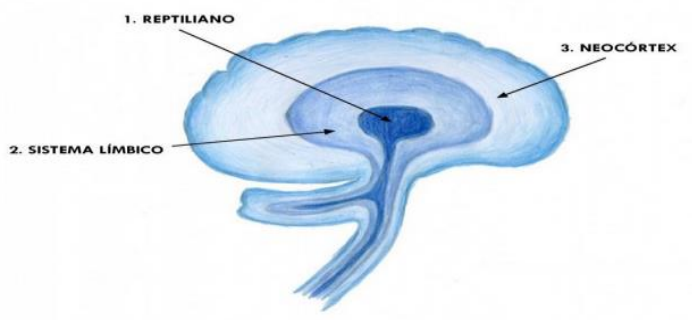

Figura 2. Proyección de la neocorteza cerebral.

Se conoce con este nombre en honor al neuropsiquiatra y anatomista Theodor Meynert, él creía que las alteraciones en el desarrollo del cerebro podían ser una predisposición a las enfermedades psiquiátricas. Existen evidencias de cambios en el flujo cerebral que se relaciona con la degeneración colinérgica vascular.

Los síntomas no cognitivos se explican en base a los desequilibrios en vías neuroquímicas de los siguientes neurotrasmisores:

Disminución de serotonina: relacionados con sintomatología depresiva cómo obsesión, compulsión y agresividad.

Disminución de noradrenalina: asociada a la depresión y a la acción psicomotora. Existe hiperactividad noradrenérgica cortical debida al aumento de la sensibilidad cortical y a la producción de noradrenalina (NA) en la corteza prefrontal y en el hipocampo. En los casos de depresión disminuye la noradrenalina y en casos de agitación aumentan los niveles de este neurotransmisor.

Disminución de acetil colina: este neurotransmisor se asocia con el deterioro cognitivo, específicamente con los problemas de memoria. Se dice que cuando los niveles de acetilcolina se encuentran en los intervalos normales se puede generar depresión.

Conservación de dopamina: se presenta con un desequilibrio de colina y dopamina. Se ha observado que cuando los niveles de dopamina aumentan de forma relativa se presentan síntomas cómo alucinaciones, trastornos de sueño y psicosis. En algunos pacientes se presenta el síndrome de Parkinson con la disminución de dopamina.

Por otra parte una evaluación neuropsicológica detallada es capaz de revelar leves dificultades cognitivas hasta 8 años antes de que la persona cumpla los criterios de diagnóstico. La deficiencia más notable es la pérdida de memoria, manifestada como la dificultad de recordar hechos recientemente aprendidos y una inhabilidad para adquirir nueva información.

Dificultades leves en las funciones ejecutivas (atención, planificación, flexibilidad y razonamiento abstracto) o trastornos en la memoria semántica (recordar el significado de las cosas y la interrelación entre los conceptos) pueden también ser síntomas en las fases iniciales del Alzheimer. Puede aparecer apatía que persiste a lo largo de la enfermedad. La fase preclínica es denominada deterioro cognitivo leve. ${ }^{4}$

Actualmente, tenemos claro que la enfermedad de Alzheimer (EA) se manifiesta por compromiso de las funciones cognitivas, síntomas psicológicos y 
conductuales de demencia y compromiso de la funcionalidad (actividades de vida diaria). Los síntomas psicológicos y conductuales de la demencia aparecen en todos los estadios de la EA, algunas veces, 2 años antes del diagnóstico. El pico de frecuencia de los trastornos se muestra en el momento de aparición en la evolución de la enfermedad. Por ejemplo, el aislamiento social ocurre 33 meses antes del diagnóstico y constituye el síntoma psicológico reconocible más temprano. Ideación suicida, depresión, paranoia y trastornos del ritmo del sueño aparecen también tempranamente en el curso de la enfermedad; mientras que agitación, alucinaciones y agresividad suelen aparecer en promedio 1-2 años después del diagnóstico. ${ }^{5}$

\section{DEMENCIA MODERADA}

Los problemas del lenguaje son cada vez más evidentes debido a una inhabilidad para recordar el vocabulario, lo que produce frecuentes sustituciones de palabras erróneas (parafasia). Las capacidades para leer y escribir empeoran progresivamente. Se reduce la habilidad de la persona de realizar sus actividades rutinarias. El paciente empieza a dejar de reconocer a sus familiares y seres más cercanos. La memoria a largo plazo, que hasta ese momento permanecía intacta, se deteriora. En esta etapa se vuelven más notorios los cambios en la conducta. Las manifestaciones neuropsiquiátricas más comunes son las distracciones, el desvarío y los episodios de confusión al final del día (agravados por la fatiga, la poca luz o la oscuridad), así como la irritabilidad y la labilidad emocional, que incluyen llantos o risas inapropiadas, agresión no premeditada e incluso la resistencia a las personas a cargo de sus cuidados. En aproximadamente el $30 \%$ de los pacientes aparecen ilusiones en el reconocimiento de personas. También puede aparecer incontinencia urinaria. ${ }^{4}$

\section{DEMENCIA AVANZADA}

La enfermedad provoca deterioro de masa muscular y se pierde la movilidad, lo que lleva al enfermo a un estado de encamamiento, incapacidad de alimentarse por sí mismo. El lenguaje se torna severamente desorganizado llegándose a perder completamente. A pesar de ello, se conserva la capacidad de recibir y enviar señales emocionales. Los pacientes no podrán realizar ni las tareas más sencillas por sí mismos y requerirán constante supervisión, quedando así completamente dependientes. Es frecuente ver extrema apatía y agotamiento. El paciente con Alzheimer no muere por la enfermedad, sino por infecciones secundarias.

Los síntomas psicóticos en particular se han asociado con una mayor densidad de ovillos neurofibrilares en la EA y se ha demostrado que los pacientes con FTD diagnosticada clínicamente tienen más probabilidades de tener delirios y agitación si la base patológica subyacente de su demencia era principalmente $A D$ (placas y ovillos). ${ }^{6}$

Las neuropatías periféricas sensoriales (NPS) afectan a casi todas las personas con demencia (97\%) en el curso de la enfermedad, y aunque fluctúan, rara vez desaparecen. Los NPS pueden presentarse antes de la demencia. Entre individuos cognitivamente normales, síntomas de depresión, la irritabilidad, la agitación y la apatía predicen una cognición más rápida disminución; algunos NPS son más poderosos predictores de deterioro cognitivo leve incidental $(\mathrm{MCl})$ que la atrofia del hipocampo. $^{2}$

Los síntomas tempranos del mal de Alzheimer pueden incluir:

- Dificultad para realizar tareas que exigen pensar un poco, pero que solían ser fáciles, tales como llevar el saldo de la chequera y aprender nueva información o rutinas

- Perderse en rutas familiares

- Problemas del lenguaje, como tener dificultad para recordar los nombres de 
- objetos familiares

- Perder interés en actividades que previamente disfrutaba y tener un estado anímico indiferente

- Extraviar artículos

- Cambios de personalidad y pérdida de habilidades sociales

A medida que la EA avanza, los síntomas son más obvios e interfieren con la capacidad para cuidarse. Los síntomas pueden incluir:

- Cambio en los patrones de sueño, despertarse con frecuencia por la noche

- Tener delirios, depresión, agitación

- Dificultad para realizar tareas básicas, como preparar las comidas, escoger la ropa apropiada o conducir

- Dificultad para leer o escribir

- Olvidar detalles acerca de hechos cotidianos

- Olvidar hechos de la historia de su propia vida y perder la noción de quién es

- Alucinaciones, discusiones, comportamiento violento y dar golpes

- Deficiente capacidad de discernimiento y pérdida de la capacidad para reconocer el peligro

- Uso de palabras erróneas, no pronunciar las palabras correctamente, hablar con frases confusas

- Retraerse del contacto social

Las personas con mal de Alzheimer avanzado ya no pueden:

- Reconocer a los miembros de la familia

- Llevar a cabo actividades básicas de la vida diaria, como comer, vestirse y bañarse
- Entender el lenguaje

Otros síntomas que pueden presentarse con el mal de Alzheimer son:

- Problemas para controlar las deposiciones o la orina

- Problemas para tragar ${ }^{4}$

Hoy en día, no hay intervenciones terapéuticas establecidas que hayan sido eficaces para detener la progresión o revertir el deterioro neuronal causado por la EA. Sin embargo, hay algunos fármacos aprobados por la FDA (Food and Drug Administration, EE. UU.) que detienen temporalmente el deterioro cognitivo, funcional y conductual. Tres de los medicamentos son inhibidores de la colinesterasa: donezepilo, rivastigmina $y$ galantamina, que incrementan las concentraciones de acetilcolina, un neurotransmisor que está involucrado en el aprendizaje y la memoria. Estos fármacos son rápidamente absorbidos por vía oral y tienen pocas reacciones adversas (náuseas, diarreas y anorexia). Varios ensayos clínicos sugieren su efectividad en el mejoramiento cognitivo y estabiliza las funciones físicas de los pacientes con EA leve a moderada. ${ }^{3}$

Ensayos clínicos sugieren que la rivastigmina (en forma de parches transdérmicos) ayuda a mantener la memoria y el conocimiento, sobre todo en pacientes con EA leve a moderada. La galantamina es un extracto de flores y bulbos de lilas y plantas relacionadas. Es un inhibidor selectivo de la acetilcolinesterasa y parece mejorar la neurotransmisión central. Su efecto es equivalente al del donezepilo. ${ }^{3}$

Se han utilizado otros muchos inhibidores colinesterásicos para el tratamiento de la EA, tales como la fisostigmina y el metrifonato y sus derivados. Estos medicamentos protegen contra el estrés oxidativo y la toxicidad amiloide pero son costosos y pueden dañar las membranas neuronales. ${ }^{3}$

Los medicamentos inmunoterapéuticos anti-amiloide beta (anti-A $\beta$ ) pueden ser los más efectivos en el tratamiento de la EA. Las concentraciones demasiado 
altas o bajas de calcio en las células nerviosas afectan

la producción, transmisión y liberación de los neurotransmisores. Antagonistas del calcio como el nimodipino, la flunarazina, verapamilo y tetrandina han sido muy utilizados. El nimodipino es un antagonista de los canales del calcio, muy lipofílico y atraviesa la barrera hematoencefálica. Inhibe el influjo de calcio y mejora la circulación sanguínea en el cerebro. Parece ser bien tolerado por los pacientes con muy pocas reacciones adversas.

El dominio de repetición en el núcleo de la pérdida helicoidal periférica (PHF) está sujeta a restricciones estructurales bastante precisas que distinguen la interacción de unión de proteínas tau-tau de la interacción de unión tau-tubulina. Esto tiene implicaciones farmacéuticas importantes, ya que sugiere que debería ser posible distinguir entre las dos interacciones de unión con los posibles inhibidores de la agregación. Lo anterior indica que un inhibidor de la agregación de tau sería de poco uso terapéutico si también perjudica la interacción normal de unión a tautubulina. ${ }^{3}$

La terapia medicina tradicional china (MTC) puede ofrecer ciertos beneficios cognitivos complementarios para tratar la EA. Una planta neuroprotectora que se usa ampliamente en medicina tradicional china como medicina herbal es Evodia rutaepapa Bentham. Evodiamine (Evo), un extracto de E. rutaecarpa Bentham, presenta propiedades benéficas, pués presenta funciones anti-EA y antiinflamatorias. ${ }^{4}$ En la tabla 1 se muestran las diferentes alternativas terapéuticas para el tratamiento de la EA.

\begin{tabular}{|l|l|}
\hline \multicolumn{2}{|c|}{ Terapias para el tratamiento de la EA } \\
\hline Actual & Implantes de células y genes. \\
\hline \multirow{2}{*}{ Tratamiento general } & Terapías farmacológicas y no farmacológicas. \\
& Terapia preventiva, curativa y sintomática. \\
& Asistencia familiar y del paciente. \\
& Tratamientos físicos y mentales. \\
\hline
\end{tabular}

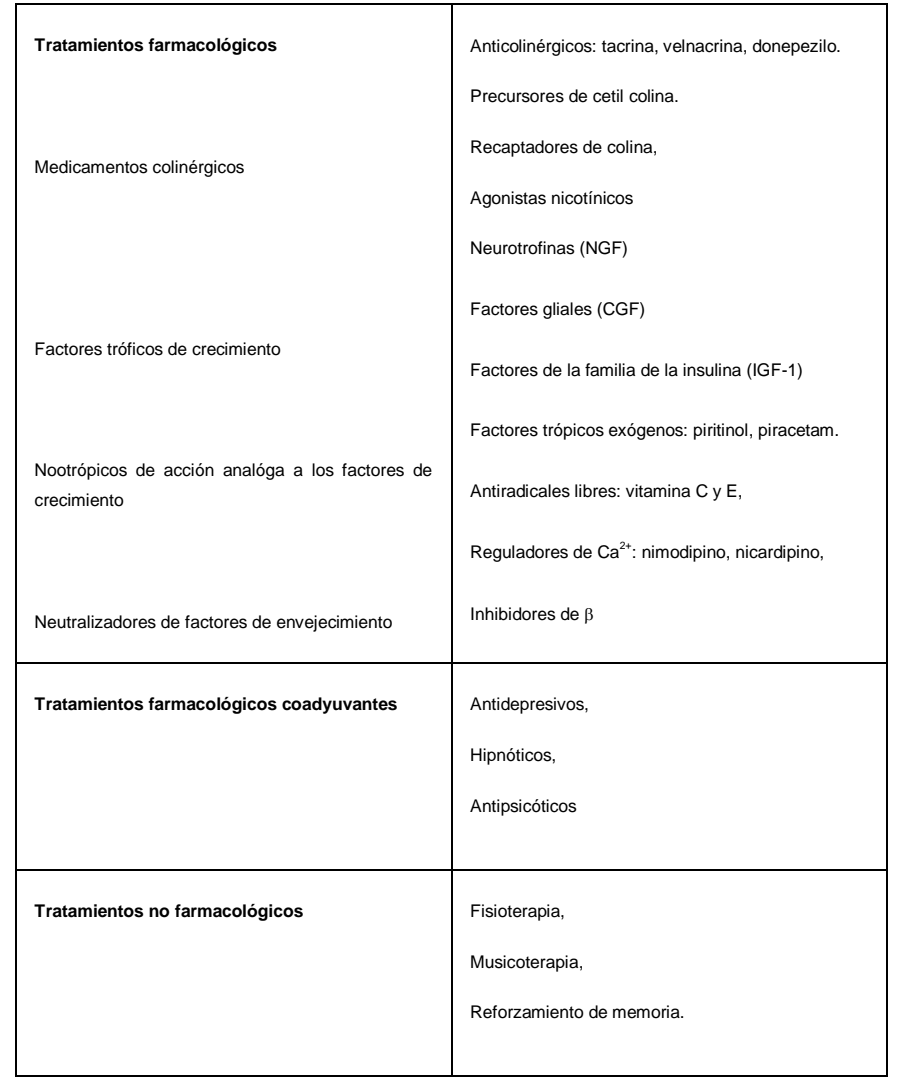

Tabla 1. Tratamientos para la enfermedad del Alzheimer.

\section{ANÁLISIS}

Si bien es sabido que existen teorías que explican la EA en pacientes que presentan la enfermedad, es importante considerar la variabilidad genética y la predisposición de heredabilidad genética de cada individuo que presenta los diferentes estadios de demencia o la EA. Es importante considerar la carga genética porque permite tener mejor información respecto a la individualidad de las personas que están predispuesta a la enfermedad o bien, ya presentan síntomas de la enfermedad. Los tratamientos varían en función del trastorno diagnosticado.

Se ha dicho que el uso de estrógenos en la mujer postmenopáusica normal podría retrasar el desarrollo de una EA; lo mismo se ha planteado con respecto a los antiinflamatorios, a los antioxidantes, y al Gingko biloba, sin llegar a una conclusión contundente. La educación disminuye el 
riesgo de sufrir demencia y permite suponer que si nos mantenemos intelectualmente activos podríamos prevenir la EA en alguna medida. Hay trabajos muy recientes que apuntan en este sentido. La actividad física el estado de salud son importantes, sobre todo si recordamos que en la EA existen alteraciones vasculares. ${ }^{1}$

Cuando existe una predisposición hacia la EA es indispensable realizar el diagnóstico de la enfermedad de forma precoz. Esto nos permite iniciar la terapia con mejores expectativas de rendimiento y evita las complicaciones derivadas de los errores del paciente y de los conflictos con su familia. En el caso de las personas que asumen el diagnóstico, les permite ejercer su autonomía con respecto a las medidas a tomar en el futuro.

\section{DISCUSIÓN}

La EA constituye aproximadamente el $70 \%$ de todos los casos de demencia. La incidencia de EA aumenta con la edad, duplicándose cada 5-10 años. Para personas entre 65 y 69 años, 70 y 74 , 75 y 79, 80 y 84 , y 85 y más, la incidencia de EA se ha estimado en $0.6 \%, 1.0 \%, 2.0 \%, 3.3 \%$ y $8.4 \%{ }^{8}$ La prevalencia se ve aumentada exponencialmente con la edad, pasando del 3\% entre los $65-74$ a casi el $50 \%$ entre los mayores de 85 años. Las lesiones características en el cerebro de los pacientes con EA se han mantenido sin cambios desde la descripción de Alzheimer de 1907. Además, se sabía que el componente de la placa neural se asociaba con la demencia senil antes de la descripción de Alzheimer y Fischer lo describió con mayor detalle. ${ }^{9}$

En 1907, Alois Alzheimer describió el caso de una mujer de 51 años que presentaba un deterioro de memoria relativamente rápido junto con trastornos psiquiátricos. Ella murió 4 años después. Si bien en ese momento se conocían diversas afecciones neurológicas progresivas y fatales, incluida la demencia senil, la edad temprana de inicio y un nuevo hallazgo patológico, el enredo neurofibrilar (NFT) hizo que esta afección fuera única asociada a otras patologías que pueden ser la causa de muerte. ${ }^{8,9}$

Actualmente la tecnología a permitido estudiar la EA conociendo los mecanismos del Sistema Nervioso Central (SNC), ya que, se conoce la patología y la fisiología de varios procesos y estructuras celulares y esto ha permitido interpretar las teorías que fundamentan la enfermedad de AE desde su etiología hasta la patología.

Las teorías más documentadas para explicar la EA son: tóxicas, infecciosas y genéticas. La primera indica que la EA se debe a la acumulación de proteínas y degeneración celular por presencia de aluminio. También se ha mencionado que los factores críticos que provocan la intoxicación en este sentido son los cationes de $\mathrm{Ca}^{2+}, \mathrm{Mg}^{2+}, \mathrm{Zn}^{2+}$, además del $\mathrm{Al}^{3+}$ que se encuentran en el medio ambiente y en la dieta. La teoría infecciosa se relaciona con los agentes causales de la enfermedad a través de virus o por presencia de "priones" que son proteínas que se replican y duplican hasta coalescer. ${ }^{10}$ Esta última relacionada con la encefalitis equina, conocida como la enfermedad de las vacas locas, que puede ser una enfermedad recesiva o por contagio por priones. Por otra parte, las teorías genéticas se basan en la neurodegeneración celular en pacientes que presentan Síndrome de Down. También existen otros genes implicados en la EA, por lo cual se considera poligénica. Existen genes que dirigen las síntesis de apopoliproteínas E en el SNC, los alelos relacionados con la EA son E2, E3 y E4 y se ha demostrado que el mecanismo patogénico de la EA es múltiple. Se ha observado alteraciones en la producción de Acetilcolina $y$ en las estructuras amiloideas y del citoesqueleto neuronal. Actualmente se ha mencionado una variante de la del operador (regulador del gen en el proceso de replicación y dirigir la síntesis de la proteína) del gen APOE, que es responsable en mayor grado en el padecimiento de la EA, en los alelos 2, $3 \circ 4$, donde las 
mutaciones en el núcleo y en las mitocondrias pueden ser los causales de la enfermedad y no propiamente la APOE.

\section{CONCLUSIÓN}

La EA es una enfermedad que presenta diferentes subtipos clínicos, anato-patológicos o bioquímicofarmacológicos por lo cual el tratamiento se centra en la prevención de la enfermedad considerando evitar la neurodegeneración o si existe que se disminuya el proceso, así como la estimulación de los mecanismos reparadores de las neuronas para disminuir la pérdida de la función neuronal y mejorar los mecanismos afectados por el mal funcionamiento de las neuronas. Lo anterior radica en la solución de problemas en la vida del paciente y retrasar su deterioro cognoscitivo para mantener al paciente de forma autosuficiente. Los tratamientos basados en medicamentos colinérgicos es la primera vía para tratar la enfermedad. Después como alternativa en el tratamiento son los factores de crecimiento o neurotróficos. Otros son los nootrópicos y los neutralizadores de los factores de envejecimiento.

\section{REFERENCIAS}

[1] Torbio, L. (2016) 800 mil mexicanos padecen Alzheimer. Excelsior. México. Recuperado de: http://www.excelsior.com.mx/nacional/2016/09/22/1118330

[2] Álvarez Sanchez, M (2008) Fisiopatología de la enfermedad de Alzheimer. Revista Mexicana de Neurociencia, 9(6): 196-201.

[3] Cabrera, M. (2014) Patogenia y tratamientos actuales de la enfermedad de Alzheimer. Revista Cubana de Farmacia, 48(2):508-518

[4] Campellone, J (2018) Mal de Alzheimer. Medlineplus. Recuperado de:https://medlineplus.gov/spanish/ency/article/000760.htm

[5] Custodio, N. (2015) Enfermedad de Alzheimer. Conociendo la enfermedad que llegó para quedarse. (editorial no especificada) Lima, Perú

[6] Ford, A. (2014) Neuropsychiatric aspects of dementia, Maturitas, 79(8): 209-215.

[7] Crespo, M. y Salgado, A. (2010). Demencia y residencia: la voz de los profesionales. News Tercera Edad, 8(10): 8-9.

[8] Wischik, C et al (2014) Tau-aggregation inhibitor therapy for Alzheimer's disease. Biochemical pharmacology, 88(1): 529539.

[9] Castellani, L et al. (2010) Alzheimer Disease,Alzheimer's asociation. 56(6): 484-546.
[10] Toledano, A. La enfermedad de Alzheimer: la demencia que pone en jaque a la sociedad del siglo XXI. ACTA. Revisado 29 de octubre del 2019 en: https://www.acta.es>medios>articulos>medicina_y_salud 